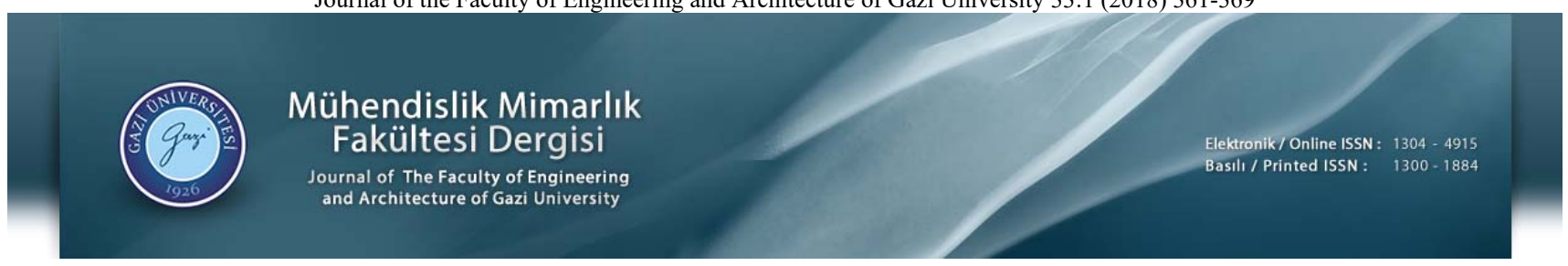

\title{
Plazma ark torçunda gaz akış debisi ve elektrik akım değerlerinin gaz çıkış sıcaklığı ve hızlarına etkisinin HAD analizi ile incelenmesi
}

\author{
Waleed Khaled Waleed Sunjuq ${ }^{(D)}$, Emre Yurtkuran*(i), Abuzer Kadir Özsunar ${ }^{\circledR}$, Rahmi Ünal(D) \\ Gazi Üniversitesi, Mühendislik Fakültesi, Makina Mühendisliği Bölümü, 06570, Ankara, Türkiye
}

\section{Ö N E C I K A N L A R}

- $\quad$ Artan debiyle ark kökünün torç çıkışına doğru kaydığı ve ark boyunun uzadığı belirlenmiştir

- Torç içinde ve çıkış kesitinde sıcaklık ve hızın radyal mesafeye göre değişiminin simetrik değildir

- Akım yoğunluğu değeri arttıkça torç çıkış kesitinde ortalama hız ve sıcaklık değerlerinin belirli bir değere kadar artma eğiliminde oldukları görülmüştür

Makale Bilgileri

Geliş: 08.09.2017

Kabul: 29.12.2017

DOI:

10.17341/gazimmfd.406807

Anahtar Kelimeler:

Plazma simülasyonu, plazma torç,

sayısal analiz

\section{ÖZET}

Termal plazma işlemleri, elektirik arkı ile üretilen ısı ile plasma gazının çok yüksek sıcaklıklara ( örn.> $10000 \mathrm{~K}$ ) ulaşmasına neden olur, teknolojik avantajlarını çok çeşitli endüstri alanlarında kanıtlamıştır. Transfer edilmeyen ark plazma torçları, orta ve yüksek sıcaklık ve hız elde edilen plazma jetlerine gereksinim duyan plazma püskürtme ve toz sentezi gibi uygulamalarda kullanılmaktadır. DC plazma ark torçlarının çoğunda üç ana bileşen vardır ve bunlar katot, plasma gazı enjeksiyon aşaması ve anot. Bu çalışmada, argon DC transfer edilmeyen ark plazma torç geometrisi tasarlanmıștır. Tasarlanan torç içindeki plazma oluşumu hesaplamalı akışkanlar dinamiği yaklaşımı ile analiz edilerek parametrik inceleme yapılmıştır. Plazma torçu üç boyutlu olarak modellenmiş, akış özelliği türbülanslı, sıkıştırılamaz ve zamandan bağımsız olarak kabul edilmiştir. Torç içerisindeki elektromanyetik alan ve gaz akışı arasındaki etkileşimi çözebilmek için ANSYS Fluent ve MHD modülü birlikte kullanılmıştır. Akım yoğunluğu ve gaz debisi değişkenlerinin torç çıkışındaki plazma jeti sıcaklığı ve hızı üzerindeki etkileri incelenmiştir. Artan akım yoğunluğu ve hacimsel debiyle torç çıkışındaki sıcaklık ve hızın artma eğiliminde olduğu, fakat artışın düzenli olmadığı görülmüștür. Torç içinde ve çıkıs kesitinde sıcaklık ve hızın radyal mesafeye göre değișiminin simetrik olmadığı tespit edilmiş olup, bunun nedeninin ark kökünün anot duvarına temas ettiği nokta ile ilgili olduğu belirlenmiștir.

\section{Investigation of the effect of gas flow rate and electric current on plasma jet temperature and velocity at torch exit by CFD analysis}

\section{H I G H L I G H T S}

- It is determined that arc root shifts to the exit of the torch and arc length increases with current increase

- Temperature and velocity profiles in the torch and at the exit in radial distance are not symmetrical

- As the current density value increases, the average velocity and temperature values tend to increase by a certain value at the cross section of torch exit

Article Info

Received: 08.09.2017

Accepted: 29.12 .2017

DOI:

10.17341/gazimmfd.406807

Keywords:

Plasma simulation, plasma torch, numerical analysis

\begin{abstract}
Thermal plasma processes, the electric heating produced by the arc causes the gas to reach very high temperatures (e.g. $>10000 \mathrm{~K})$, have proven their technological advantage in a wide variety of fields of industry. Non-transferred arc torches are typically used in applications that rely on the formation of a plasma jet with moderate to very high velocity and high temperature processing medium, such as plasma spraying and powder synthesis. Most DC arc torches have three main components: The cathode, the plasma forming gas injection stage, and the anode. In this study, argon DC non-transferred arc plasma torch geometry was designed. The plasma formation in the designed torch was simulated by a computational fluid dynamics (CFD) approach and parametric analysis was performed. Plasma torch was modelled three dimensional and the plasma flow was considered as steady, turbulent and incompressible. ANSYS Fluent and MHD modules were used together to solve the interaction between the electromagnetic field and the gas flow in the torch. Current density and gas mass flow rate were the parameters to investigate their effects on the plasma temperature and velocity at the torch exit. It was observed that there is a tendency for increase of temperature at the exit of the torch with increasing current and mass flow rate, but there is no monotonic increase. In addition, temperature and velocity profiles at the torch exit are not symmetrical in radial distance because of the the arc root attachment point on the anode wall surface.
\end{abstract}




\section{GİRİS (INTRODUCTION)}

Günümüzde plazma torçları farklı teknolojiler geliştirilerek kesme işleminde, püskürtme kaplama işlemlerinde, metal tozu üretiminde, imalatta, atık yok edilmesinde, tıpta, 1̧̧ıklandırmada, enerji üretmekte, kaplama işlemlerinde ve daha birçok teknolojide kullanılmaktadır [1]. Pazma atık yok etme sistemleri diğer yakma teknolojilerine göre daha az atık açığa çıkarması nedeniyle daha çevreci bir yaklaşımdır [2]. Ayrıca plazma yüzey kaplama yöntemi farklı amaçlarla yaygın bir şekilde uygulanmaktadır [3]. Plazma torçları, transfer edilen ark ve transfer edilmeyen ark olarak iki tür şeklinde çalışmaktadır [4]. Geleneksel bir DC transfer edilmeyen ark plazma torcu (endüstriyel torçların \%90'ını temsil eder) ve içerisindeki plazma arkının şematik görünümü Şekil 1'de gösterilmektedir.

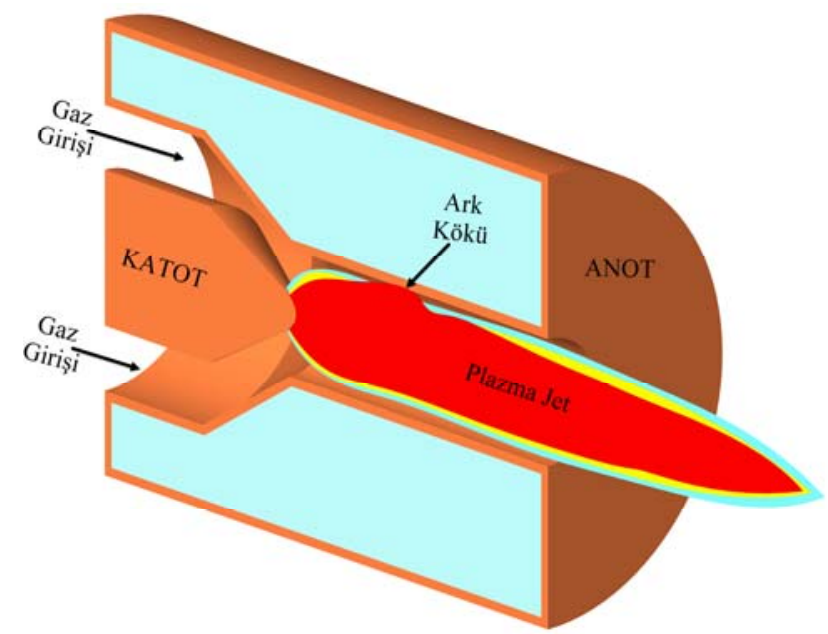

Şekil 1. DC Transfer edilmeyen plazma ark torçu ve plazma jetin şematik görünümü

(Schematic view of DC non-transferred plasma arc torch and plasma jet)

Plazma teknolojisinin kullanıldığı uygulamaların kalitesi plazma torcu ile oluşturulan plazma jetinin sıcaklık ve hızına bağlıdır. Plazma torçu içindeki fiziksel ve kimyasal süreçler torç çıkışında oluşan plazma jetinin özelliklerini önemli derecede etkilediği için plazma torçu iç kısmında meydana gelen plazma oluşumu ve plazma özellikleri üzerine çok sayıda teorik çalışmalar yapılmaktadır. Torç boyutunun çok küçük olması nedeniyle torç içinde oluşan plazma ile ilgili deneysel veriler elde etmek zor ve çok yüksek masraflı olduğundan dolayı, hesaplamalı akışkanlar dinamiği çözümleri ile plazma torçu içinde elde edilen sıcaklık ve hız verileri oldukça kullanışlı bilgiler sunmaktadır [1]. Bu sayede amaca yönelik olarak uygun torç geometrisinin oluşturulması ve deneysel çalışmaların sayısının azaltılması bağlamında sayısal analizler oldukça kullanışlıdır. Literatür araştırması sonucunda konu ile ilgili yapılan simülasyon çalışmalarında iki boyutlu (2B) ve üç boyutlu (3B) yaklaşımların kullanıldığı görülmektedir. Ancak yapılan incelemelerde plazma torçu içinde oluşan ark nedeniyle torç kesitinde radyal yönde oluşan sıcaklık ve hız dağılımlarının simetrik ve homojen olmadığı görülmektedir [5]. Bu nedenle bu çalışmada 3B sayısal çözümün yapılmasının daha gerçekçi olacağı değerlendirilmiştir. Literatürde sunulan çalışmalarda, ark bağlantısı her zaman anot duvarına sıkışmış bir yer olarak kabul edilmekte ve anot iç yüzeyi boyunca ark kökü bağlantı konumunun belirlenmesi 3B modellemede önemli bir kazanım olarak gözükmektedir [6]. Literatürde mevcut çalışmaların genelinde bir DC plazma torçundaki ark kökü eklenme konumu Steenbeck prensibi veya minimum entropi ilkesi esas alınarak elde edilmiştir [7]. Ayrıca başka bir yaklaşım olarak termal verimlilik kriteri de Eichert vd. [8] ile Meillot vd. [9] tarafından kullanılmıştır. Ramachandran vd. [6] tarafindan yapılan çalışmada, girişe çok yakın bölgede gazın sıcaklığında keskin bir artış olduğu için ilgili denklemlerin çözümünde rraksama tespit edilmiş, bu hatayı önlemek için girişteki gazın sıcaklığı $3500 \mathrm{~K}$ olarak sabitlenmiştir. Literatürde sunulan sayısal analizler incelendiğinde çalışmalarda genel olarak torç içindeki ve çıkış kesitindeki plazma jetinin hız ve sıcaklık dağılımlarının incelendiği görülmüştür. Ancak özellikle plazma atomizasyon işlemine yönelik olarak hız ve sicaklik değerlendirmelerinin birlikte yapılmadığı görülmüştür.

Sunulan çalışma ile özellikle plazma atomizasyon yöntemi ile metal tozu üretimine yönelik olarak tasarlanmas1 planlanan plazma torçunun sayısal analizlerinin yapılması ve torç çıkış kesitindeki hız ve sıcaklık dağılımın birlikte değerlendirilerek en uygun çalışma şartlarının belirlenmesi hedeflenmiştir. Bu amaçla, plazma torcu içerisinde oluşan plazmanın özellikleri hakkında temel bilgi elde edilmesi ve ark ile ortam gazı arasındaki etkileşime gaz akış debisi ve elektrik akımının etkisi hesaplamalı akışkanlar dinamiği yaklaşımı ile incelenmiştir. Argon gazı için zamana bağlıee olmayan kararlı durum şartlarında plazma torcunda plazma oluşumuna yönelik üç boyutlu (3B) sayısal analizler yapılmıştır. Analizlerde elektromanyetik alan ve gaz akışı arasındaki etkileşimi çözebilmek için Ansys Fluent ve Manyetohidrodinamik (MHD) modülü birlikte kullanılmıştır. Gaz giriş debisi ve akım değerinin plazma torcu içindeki ve çıkış kesitindeki sıcaklık ve hız profillerine etkisine dair veriler sunularak değerlendirilmiştir.

\section{TEORİK YÖNTEM (THEORETICAL METHOD)}

\subsection{Plazma Arkı (Plasma Arc)}

Plazma oluşumu ile ilgili literatür ışığında aşağıdaki varsayımlarda bulunulmuştur.

- Yerçekimi kuvveti ve viskoz kayıpları, kinetik etkiler ile karşılaştırıldığında çok az olduğu için ihmal edilmiştir.

- Matematiksel formülleri basitleştirmek için plazma bölgesel termodinamik dengede (BTD) varsayılmıştır. Sonuç olarak plazma gazı tek bir sıcaklık ile karakterize edilen sürekli akışkan olarak değerlendirilir [7].

- BTD varsayımına dayanarak, plazma gazının (cp, $\mu$ ve $\lambda$ gibi) termodinamik ve taşıma özellikleri elektriksel 
iletkenliği $(\sigma)$ hariç tutularak gaz sıcaklı̆̆ tarafından belirlenir [13].

- Deneysel çalışmalar ark kökü eklentisinin oluşturduğu erozyon noktasını sabit bir nokta gösterdiğinden ark işleminin kararlı durumda olduğu varsayılmıştır. Bu yüzden denklemler zamana bağlı değil sürekli durum için çözülmüştür [16].

- Plazma akışı, sürekli, türbülanslı ve sıkıştırılamaz olarak kabul edilmiştir. Hızlı ısınma ark etrafında ani genişlemeye ve sonucunda hızlı ivmelenmesine sebep olur bu ise akışı türbülanslı yapar [10].

- Kullanılan gaz (argon) plazma torç eksenel yönünde enjekte edilir, bu yüzden torç girişinde hiçbir girdap hızı ortaya çıkmaz [11].

- Elektrik beslemesi sabit bir güç değerine sahip kararlı durumdadır. İndüklenen elektrik alanı, plazma ark bölgesinde uygulanan elektrik alan şiddeti ile karşılaştırıldığında önemsizdir [12].

\subsection{Ana Eşitlikler (Governing Equations)}

Plazma jet modelleme de kullanılan eşitlikler kütlenin, momentumun ve enerjinin korunumu denklemlerini içerir. Plazma oluşumunda kritik olan ark kısmının modellenmesinde temel alınan eşitlikler ise Maxwell denklemleri tarafindan elektrik potansiyeli ve manyetik vektör potansiyeli biçiminde verilen elektromanyetik denklemlerdir ve Eş. 1-Eş. 10 arasında verilmiştir.

$\nabla \cdot \rho \mathrm{v}=0$

$\nabla \cdot(\rho v v)=-\nabla \mathrm{p}+\nabla \cdot \overleftrightarrow{\tau}+\mathrm{j} \times \mathrm{B}$

$\nabla \cdot(-\sigma \nabla \emptyset)=0$

$\vec{E}=-\nabla \emptyset$

$\Delta \vec{A}=-\mu_{0} \vec{J}$

$\vec{B}=\nabla \times \vec{A}$

$\nabla \cdot j=0$

$\vec{J}=\sigma \vec{E}$

$j=\sigma(-\nabla \emptyset+v \times \mathrm{B})$

$\nabla \cdot(\sigma \nabla \emptyset)=\nabla \cdot(\sigma \vee \times B)$

Plazma torcu içerisine iletilen gazın, ark dolayısıyla aniden 1sınması ve ark etrafındaki genişlemeye bağlı olarak aniden ivmelenmesi, akışı türbülanslı hale getirmektedir. Güvenilir çözüme ulaşabilmek ve türbülanslı akışı modelleyebilmek adına k- $\varepsilon$ türbülans model kullanılmıştır. Modele ait matematiksel eşitliklerden türbülans kinetik enerjisi $(\mathrm{k})$ Eş.11 ve türbülans yayınım oranı $(\varepsilon)$ ise Eş. 12'de verilmiştir.

$$
\begin{aligned}
& \nabla \cdot(\rho \mathrm{kv})=\nabla\left[\left(\mu+\frac{\mu_{t}}{\sigma_{k}}\right) \nabla \mathrm{k}\right]+G_{k}-\rho \varepsilon \\
& \nabla \cdot(\rho \varepsilon \mathrm{v})=\nabla \cdot\left[\left(\mu+\frac{\mu_{t}}{\sigma_{\varepsilon}}\right) \nabla \varepsilon\right]+\frac{\varepsilon}{k}\left(C_{1 \varepsilon} G_{k}-\rho \varepsilon C_{2 \varepsilon}\right)
\end{aligned}
$$

\subsection{Hesaplama alanı ve Sınır Şartları (Computational Domain and Boundary Conditions)}

Hesaplama yapılan alanın şematik gösterimi Şekil 1'de, a g yapısı ile ayrıntılı gösterimi ise Şekil 2'de yer almaktadır. Hesaplama alanına ait sınır şartları Tablo 1'de verilmiştir. Sıcaklığın ani yükseldiği aşikar olduğundan ıraksamadan kaçınmak amaciyla katot sicaklığı $3500 \mathrm{~K}$, soğutma suyu sıcaklığı hesaplamalara katılmamış ve anot yüzeyinin sıcaklığı sabit $1000 \mathrm{~K}$ olarak alınmıştır. Geçerli çözüm modeli için k- $\varepsilon$ türbülans modeli, ikinci dereceden çözüm ve algoritma olarak ise Coupled kullanılmıştır.

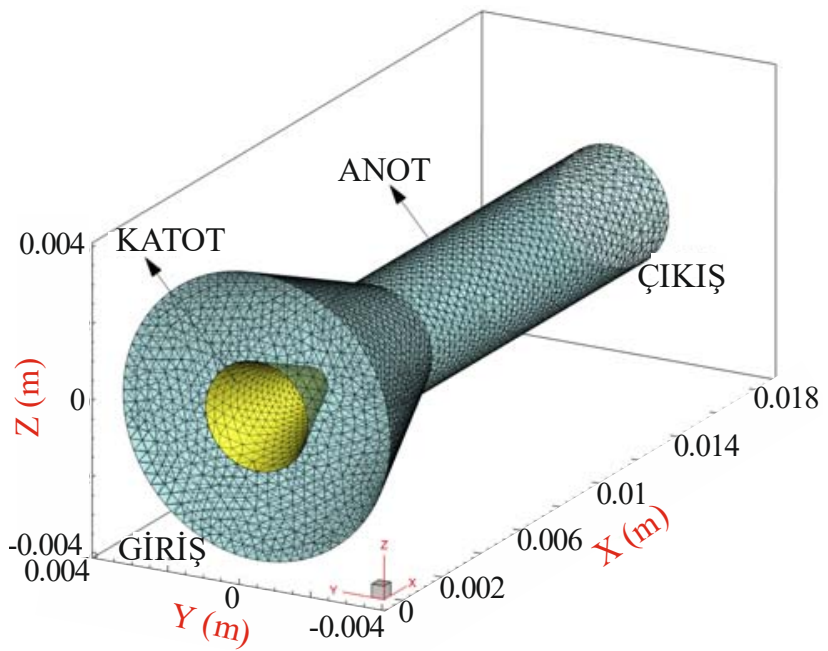

Şekil 2. Plazma torcu hesaplama alanı geometrisi ve ağ yapısının görünümü

(View of the computational domain geometry and mesh structure of the plasma torch)

Çözüm alanı farklı sayılarda elemanlara bölünerek uygun eleman sayısı ă̆ sayısından bağımsızlaştırılarak elde edilmiş ve çözümlemeler elde edilen sayılardaki elemanlarla yapılmıştır. Parametrik çalışmalar için kullanılan eleman sayıları 20500 ve 106000 arasında değişmektedir. A $\breve{g}$ yapısından bağımsızlık kontrolü torç içerisinde elde edilen en yüksek sıcaklığa ve en yüksek hıza göre çift taraflı kontrol edilmiştir. Bu sıcaklık ve hız değerleri hücre sayısına göre 77000 değerinden sonra 106000 değerine kadar kayda değer bir değişiklik göstermemiştir. Bu testler esas alınarak 77000 hücre sayısı ile çözümlere devam edilmiştir. Ağ yapısı kalite kontrolü, sırasıyla çarpıklık (skewness) ve dikey kalite (orthogonal quality) değerleri 0,79 ve 0,27 olacak şekilde çözüm yapılmıştır. 800 ile 4800 iterasyon yapılarak gerçekleştirilen bağımsızlık testleri sonucunda 3000 iterasyondan sonra sicaklık ve hız değerlerinde değişim olmadığı görülmüştür. Plazma gazı olarak argon kullanılmıştır. Argon gazının yüksek sıcaklıklardaki ısıl ve elektriksel davranışını tam anlamıyla simüle edebilmek için 1sıl iletkenlik, entalpi, viskozite, elektrik iletkenliği gibi 
değerler kaynak [14] çalışmalarından alınarak analiz öncesinde veri girişleri programa girilmiştir.

Tablo 1. Modelde kullanılan sınır şartları (Boundary conditions used in the model.)

\begin{tabular}{|c|c|c|c|c|}
\hline & Giriş & Katot & Anot & Çıkış \\
\hline$P$ & $3 \mathrm{Bar}$ & $\partial P / \partial n=0$ & $\partial P / \partial n=0$ & 101325 \\
\hline $\mathrm{T}$ & $300 \mathrm{~K}$ & $3500 \mathrm{~K}$ & $1000 \mathrm{~K}$ & $\partial T / \partial n=0$ \\
\hline $\mathrm{V}$ & $\begin{array}{l}25-50-70 \\
\text { SLPM }\end{array}$ & 0 & 0 & $\partial v / \partial n=0$ \\
\hline I & $\partial I / \partial n=0$ & $\begin{array}{l}0,7 \times 10^{8}- \\
2,1 \times 10^{8} \mathrm{~A} / \mathrm{m}^{2}\end{array}$ & $\partial I / \partial n=0$ & $\partial I / \partial n=0$ \\
\hline A & $\partial A / \partial n=0$ & $\partial A / \partial n=0$ & $\partial A / \partial n=0$ & $\partial A / \partial n=0$ \\
\hline
\end{tabular}

\section{SONUÇLAR VE TARTIŞMALAR} (RESULTS AND DISCUSSIONS)

\subsection{Farklı Debilerde Ar Gazının ÇıkışSıcaklı̆̆ı ve Hızı Üzerine Etkisi}

(The Effect of Different Mass Flow Rates on the Outlet Temperature and Velocity of Ar Gas)

Sunulan çalışmada yapılmış olan hesaplamalı akışkanlar dinamiği (HAD) analizlerinin güvenilirliğini doğrulamak amacıyla literatürde mevcut olan iki farklı çalışma değerleri ile karşılaştırma yapılmıştır. Karşılaştırma yapılabilmesi için her bir çalışmanın çıkış kesitinde yatay ve dikey eksende elde edilmiş olan sıcaklık ve hız değerlerinin radyal mesafeye göre değişimi belirlenerek iki eksenin ortalaması hesaplanmıştır. Çalışmalarda uygulanan torç gemoterisi, iç çapı ve diğer değişkenler farklı olduğu için her çalışmanın ortalama değerleri normalize edilmiştir. Sıcaklık ve hız değerleri kendisinin en yüksek sıcaklık ve hız değerine bölünerek, radyal mesafelerde kendi yarıçapına bölünerek normalize edilmiştir. Normalize edilmiş olan değerler tek bir grafikte karşılaştırmalı olarak Şekil 3'te verilmiştir. Selvan ve Ramachandran [15] yaptıkları çalışmada $8 \mathrm{~mm}$ çaplı torç, argon gazı ve 400 A akım değerlerinde, He-Ping Li ve diğerleri [1] ise torç çapını 8mm, akım 400 A ve 34 SLPM akış debisi uygulayarak HAD analizlerini yaparak çıkış kesitinde hiz ve sicaklık profillerini vermişlerdir. Karşılaştırmada kullanılan mevcut çalışma değerleri ise torç çapı 3,2 mm, 200 A akım, 37 SLPM gaz akış debisidir. Karşılaştırma grafiği incelendiğinde her üç çalışma için veri alınan eksene göre sıcaklık ve hızın radyal mesafeye göre değişiminde farklılık olduğu görülmektedir. Bunun nedeni ark kökünün anot duvarına temas ettiği nokta ile ilgilidir. Arkın temas ettiği tarafta sıcaklık ve hızın daha yüksek olduğu ve orta eksene göre değerlerin ark kökü olan tarafta daha yüksek olduğu Şekil 4'te alınan hız ve sicaklık profillerinde görülmektedir. Karşılaştırma yapılan düzlemlerde normalize edilmiş sıcaklık ve hız grafiklerinin tam benzerlik göstermemesinin nedeninin ark kökünün konumu ile ilişkili olduğu değerlendirilmektedir. Torç geometrisi, boyutları ve çalışma parametrelerinin farklı olması dikkate alındığında, sunulan çalışmada elde edilmiş olan sıcaklık ve hız analizlerinin kabul edilebilir olduğu değerlendirilmiştir. Ark boyunun belirlenmesi torç içerisindeki 1sıl ve elektriksel durumların doğru bir şekilde analiz edilmesine ve torç çıkışındaki sıcaklık ve hız değerlerine etkisinin yorumlanmasına katkı sağlamaktadır. Ark kökünün konumunu tespit etmek ve orta eksen doğrultusunda akış debisinin sıcaklık ve hız profillerine etkisini göstermek amaciyla katot ucundan itibaren $2 \mathrm{~mm}$ ara ile orta eksene dik kesit düzlemleri oluşturularak Şekil 4'te verilmiştir. Şekilde ayrıca farklı hacimsel akış debilerinde elde edilen sıcaklık ve hız akış profilleri gösterilmiştir. En yüksek sıcaklık değerleri $15000 \mathrm{~K}$ ile $16000 \mathrm{~K}$ arasında, en yüksek hız değerleri ise $1800 \mathrm{~m} / \mathrm{s}$ ile $2300 \mathrm{~m} / \mathrm{s}$ arasında değişmektedir. Akış hızının torcun çıkışına doğru arttığı ve çıkış kesitinde en yüksek değere ulaştı̆̆ı görülmektedir.
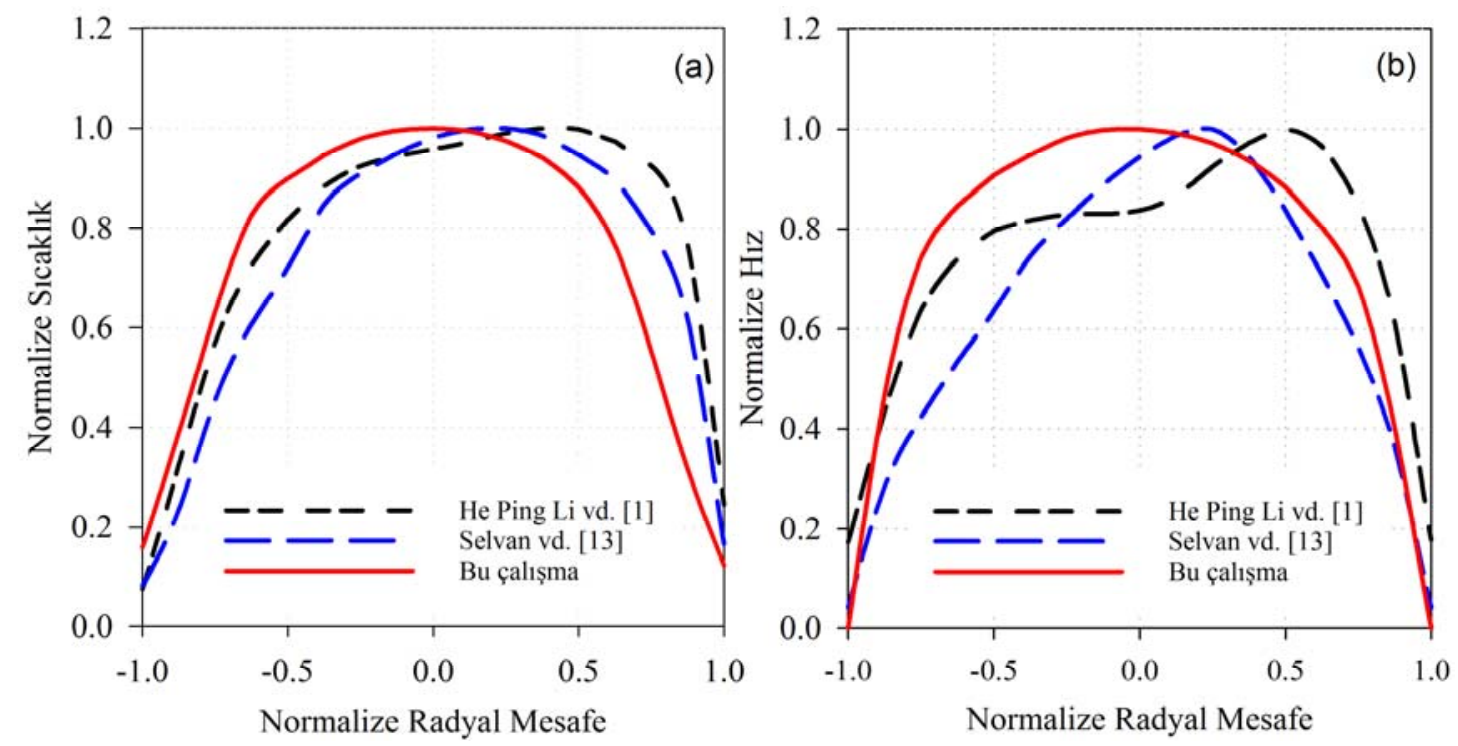

Şekil 3. Torç çıkış kesitinde radyal mesafeye göre sıcaklık ve hız profillerinin normalize edilmiş değerlerinin karşılaştırılması a) sıcaklık b) hız profili karşılaştırmaları

(Comparison of normalised temperature and velocity profiles at the torch exit a) temperature b) velocity profiles comparisons) 
Ayrıca sıcaklık değişimleri incelendiğinde sıcaklığın katot ile ark kökü arasında en yüksek değerlere ulaştığı, mesafenin artışı ile sıcaklıklarda düşme olduğu ve çıkış kesitinde daha düşük değerlere ulaştığı tespit edilmiştir. Ayrıca artan gaz akış debisi ile ark kökü mesafesinin çıkışa doğru kaydığ tespit edilmiştir. Plazma torcunun endüstriyel uygulamalarda kullanılabilirliği için önemli parametrelerden olan çıkış kesitinde radyal yönde sicaklık ve hız değerleri incelenmiştir. Hacimsel akış debisinin torç çıkış kesitindeki sıcaklık profiline etkisini inceleyebilmek için 1,45 A/m² akım yoğunluğu ve 3 bar basınç altında 25, 50 ve 70 SLPM argon gaz giriş debisi değerlerinde analiz yapılmış ve karşılaştırmalı sıcaklık ve hız profilleri Şekil 5'te verilmiştir.

Çıkış kesitinde sıcaklık ve hız profilinin orta eksene göre simetrik olmaması nedeniyle karşılaştırma yapabilmek amacıyla $Y$ ve $Z$ ekseninde radyal mesafeye göre alınmış olan sıcaklık ve hız değerlerinin ortalaması alınarak

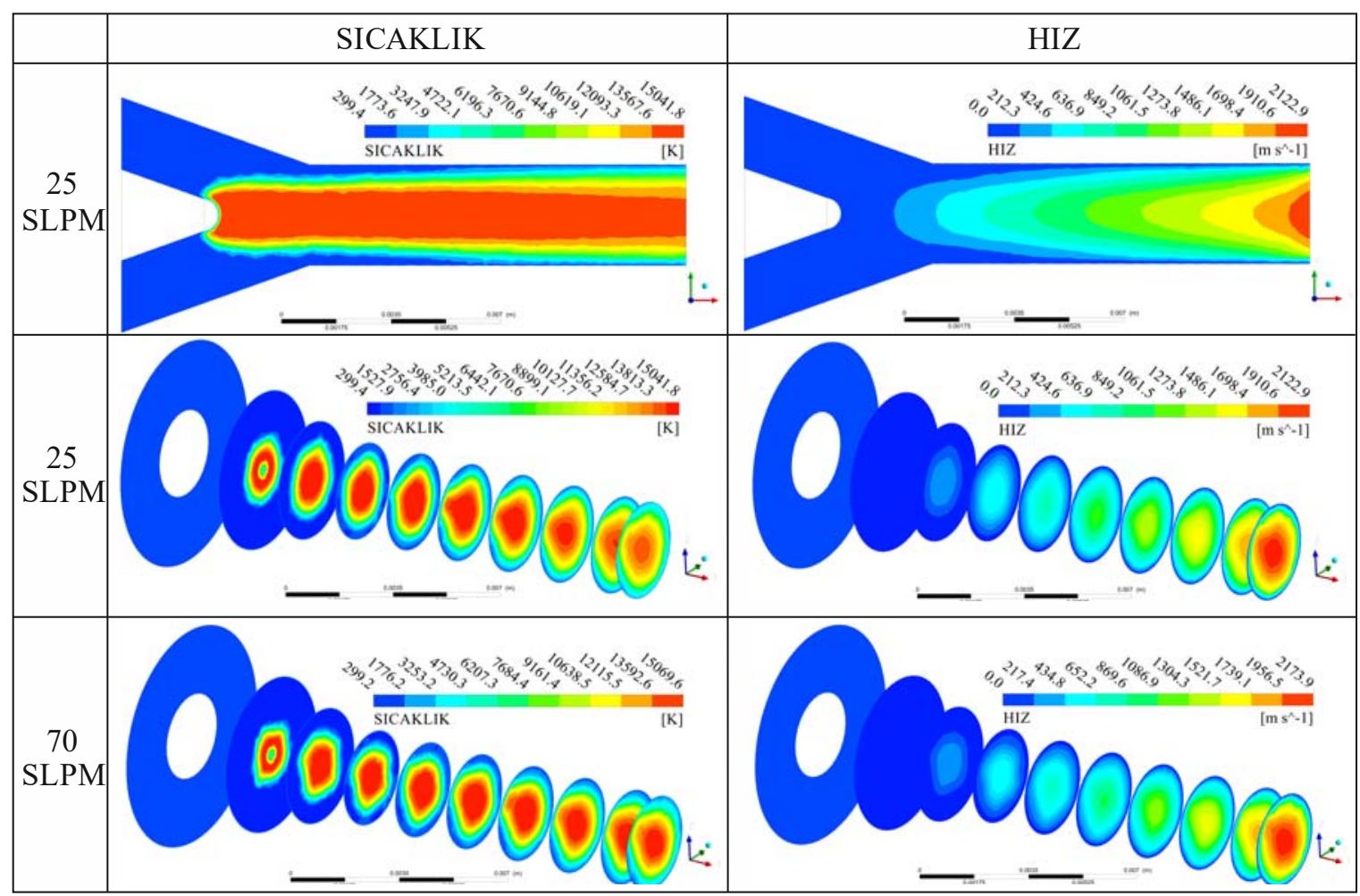

Şekil 4. Gaz akış debisinin torç içi ve çıkış kesitindeki sıcaklık ve hız profillerine etkisi (The effect of gas flow rate on the temperature and velocity profiles in the torch and at the exit)
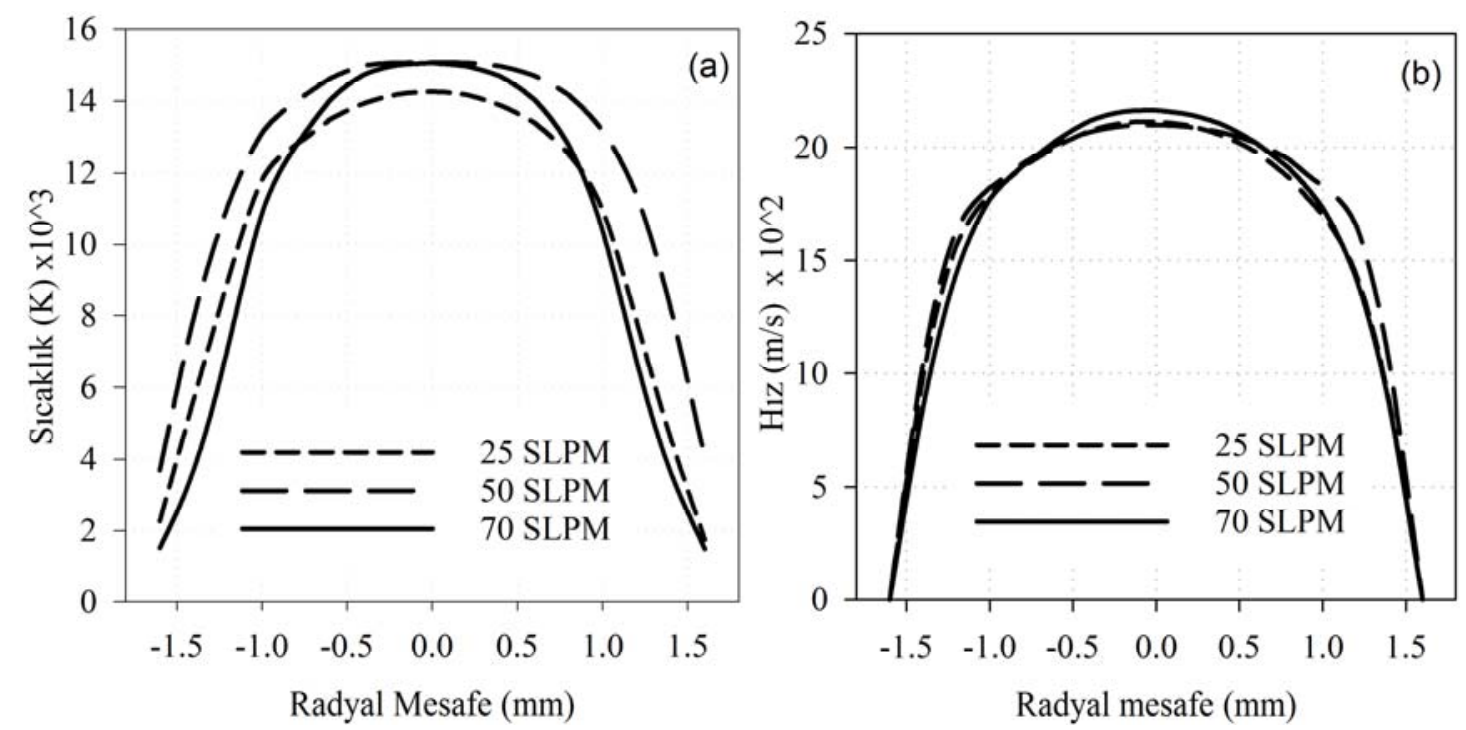

Şekil 5. Gaz giriş debisinin torç çıkış kesitinde sıcaklık ve hız profiline etkisinin karşılaştırılması a) sıcaklık profili b) hız profili (The effect of gas flow rate on the temperature and velocity profiles at the torch exit) 
karşılaştırma grafiklerinin çizilmesinde bu değerler kullanılmıştır.

\subsection{Farklı Akım Yoğunluklarının Ar Gazının Çıkış Sıcaklı̆̆} ve Hizı Üzerine Etkisi

(Effect of Different Current Densities on the Outlet Temperature and Velocity of Ar Gas)

Farklı akım yoğunluklarının etkisini görebilmek amacıyla debi değişiminden elde edilen bulgular değerlendirilmiş ve
37 SLPM sabit debide 150, 200, 250 Amper değerlerine karşılık gelen akım yoğunluğu parametreleriyle ikincil çözümler yapılmış, argon gazının çıkış kesitinde sıcaklık ve hız üzerinde etkileri değerlendirilmiştir. Şekil 6'da farklı akım yoğunluklarının çıkış parametreleri üzerine etkisini inceleyebilmek için radyal mesafelerden değerler alınarak grafikler çizilmiştir. Ark kökünün anot duvarına temas ettiği tarafta sıcaklık ve hızın daha yüksek olduğu ve orta eksene göre değerlerin ark kökü olan tarafta daha yüksek olduğu
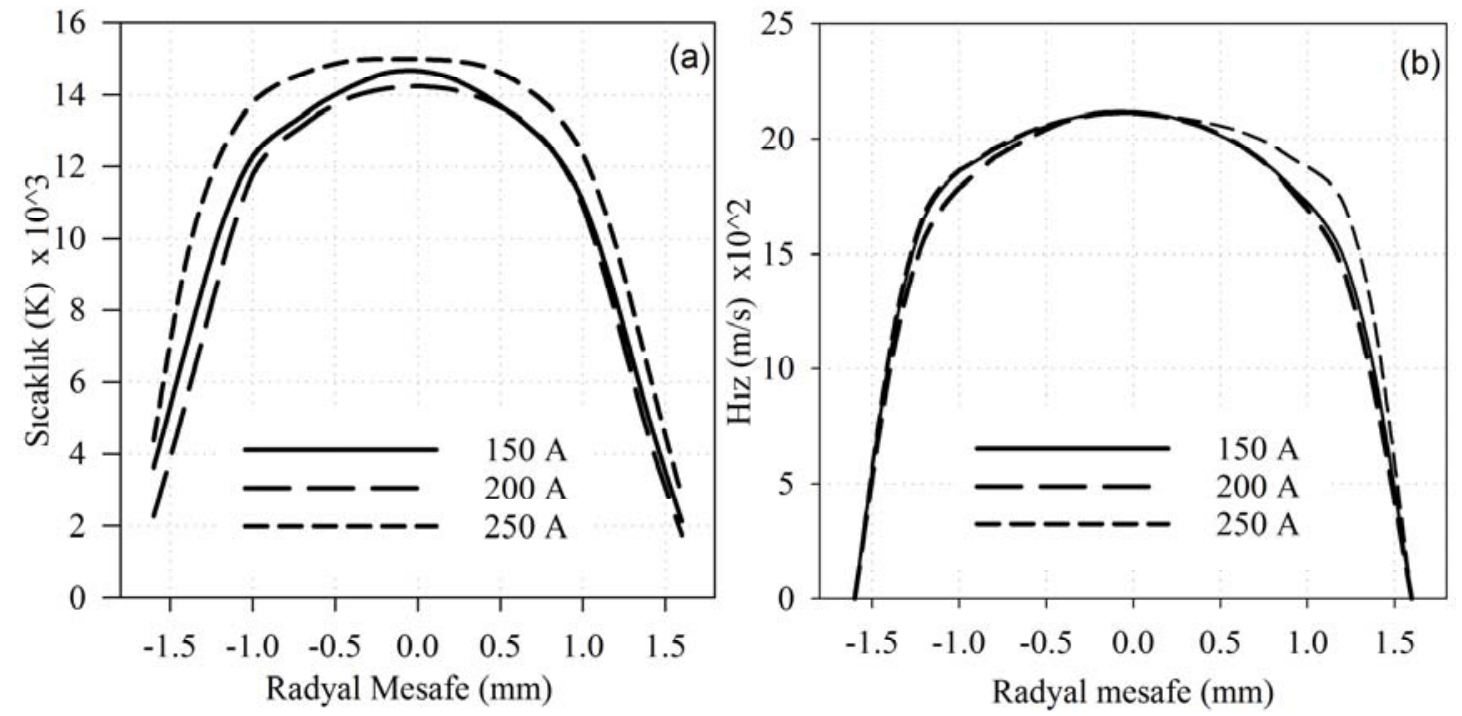

Şekil 6. Elektrik akım değerlerinin torç çıkış kesitinde sıcaklık ve hız profiline etkisinin karşılaştırılması a) sıcaklık profili

b) hiz profili (Comparison of the effect of electric current on the velocity and temperature profiles at the torch exit)

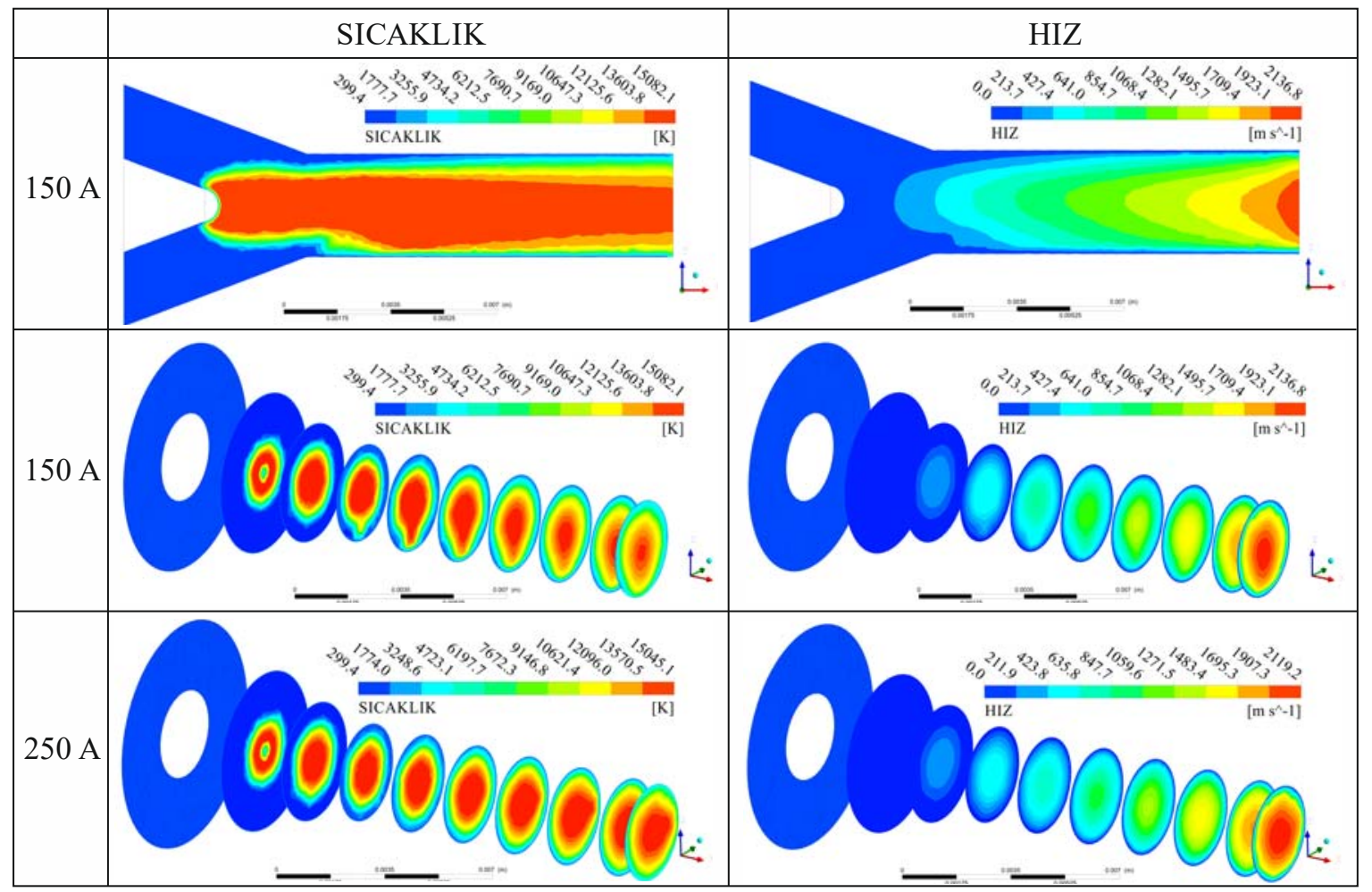

Şekil 7. Elektrik akım değerinin torç içi ve çıkış kesitindeki sıcaklık ve hız profillerine etkisi (The effect of current density on the temperature and velocity profiles in the torch and at the exit) 
Şekil 7'de gösterilen hiz ve sicaklık profillerinde görülmektedir. Bu nedenle, iki farklı $\mathrm{Y}$ ve $\mathrm{Z}$ eksenindeki sıcaklık ve hızın ortalama değerleri hesaplanarak karşılaştırma grafikleri çizilmiştir. Grafikler incelendiğinde akım artışının çıkış kesitinde sıcaklık ve hız dağılımını önemli oranda değiştirmediği görülmüştür. Akım değerlerine göre çıkış kesitindeki sıcaklık ve hız profillerinde doğrusal bir artış veya azalış tespit edilmemiştir.

Ark kökünün konumunu tespit etmek ve orta eksen doğrultusunda akım değerinin sicaklık ve hız profillerine etkisini üç boyutlu olarak göstermek amacıyla katot ucundan itibaren $2 \mathrm{~mm}$ ara ile orta eksene dik kesit düzlemleri oluşturularak Şekil 7'de verilmiştir. En yükssek sıcaklık değerleri $15000 \mathrm{~K}$ ile $15500 \mathrm{~K}$ arasında, hız değerleri ise $1800 \mathrm{~m} / \mathrm{s}$ ile $2300 \mathrm{~m} / \mathrm{s}$ arasında değişmektedir. Akış hızının torcun çıkışına doğru arttığı ve çıkış kesitinde en yüksek değere ulaştığı görülmektedir. Ayrıca sıcaklık değişimleri incelendiğinde sıcaklığın katot ile ark kökü arasında en yüksek değerlere ulaştığı, mesafenin artışı ile sıcaklıklarda düşme olduğu ve çıkış kesitinde en düşük değerlere ulaştığ tespit edilmiştir. Ayrıca artan akım yoğunluğu ile ark kökü mesafesinin arttığ 1 tespit edilmiştir.

\section{3 Çıkış Kesitinde Ortalama Sicaklık ve Hız Değerleri (Average Temperature and Velocity Profiles at the Torch Exit)}

Plazma torcunun çıkış kesitinde sıcaklık ve hız profillerinin simetrik olmaması nedeniyle çıkış kesitinde bütün hücre bağlantı noktalarındaki sıcaklık ve hız değerlerin ortalaması alınarak ortalama değerler hesaplanmıştır. Ortalama değerlerin hesaplanmasına yönelik olarak 37 SLPM ve 250 A akım değerinde yapılan analiz sonucuna göre çıkış kesitindeki ağ yapısı ve sıcaklık ve hız dağılım profilleri Şekil 8'de gösterilmiştir. Ortalama değerlerin hesaplanmasında bütün hücre bağlantı noktaları kullanılarak mümkün olduğunca karşılaştırılabilir bir veri elde edilmesi
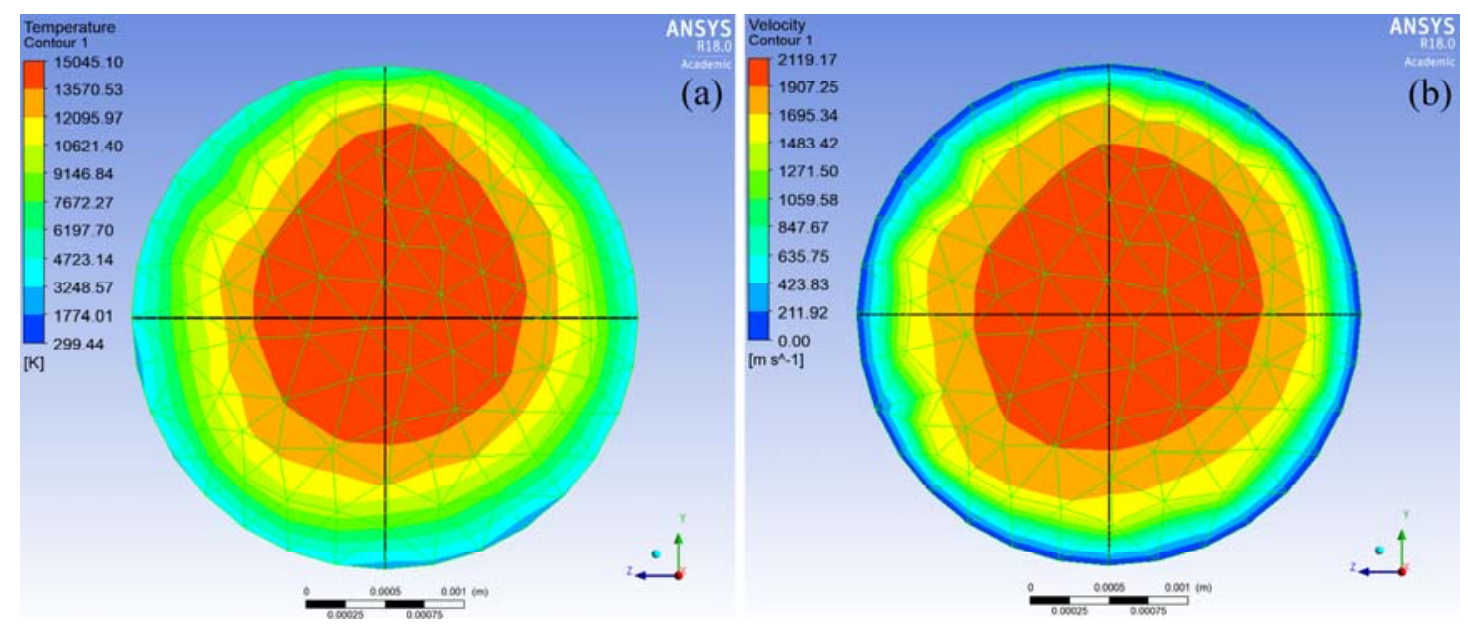

Şekil 8. Çıkış kesitinde ortalama sıcaklık ve hız değerlerinin hesaplanmasında kullanılan ağ bağlantı noktalarının görünüşü a) Sıcaklık dağılımı b) hız dağılımı (The appearance of the mesh nodes used to calculate average temperature and velocity values at the exit section a) temperature distribution b) velocity distribution)
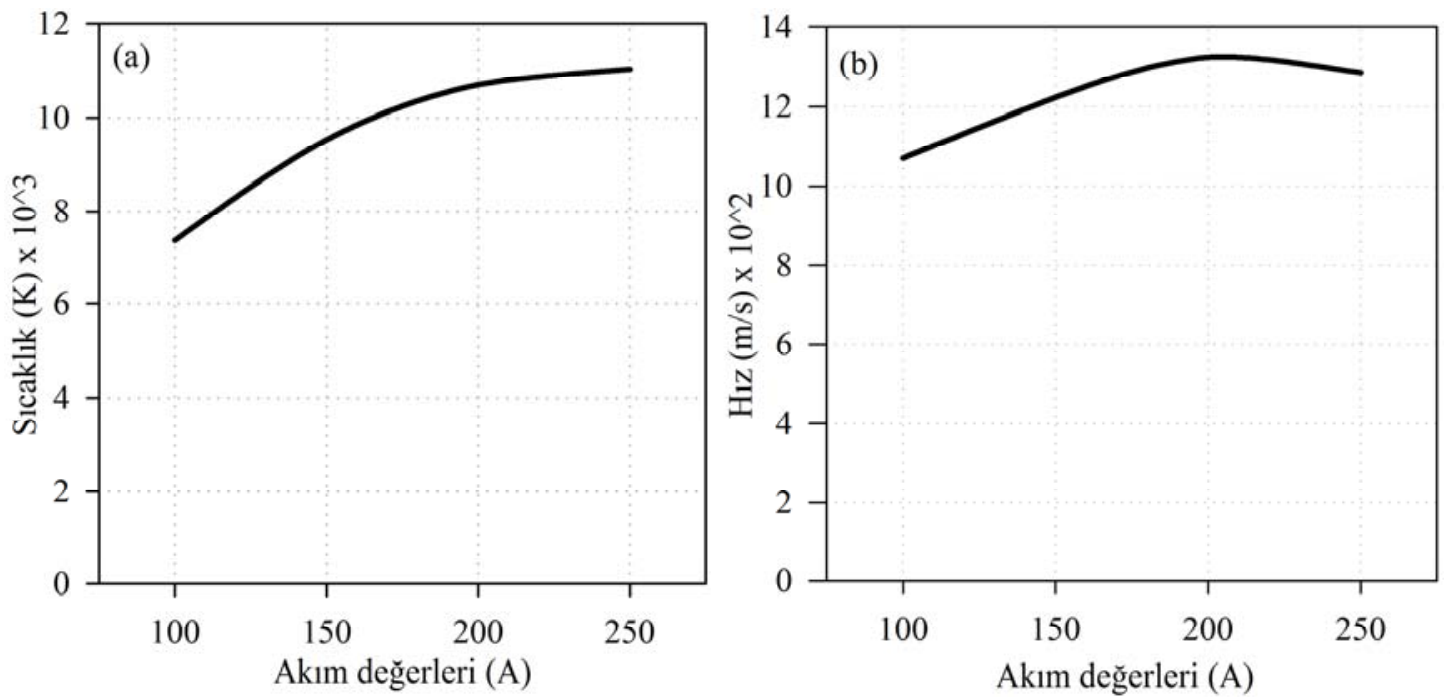

Şekil 9. Torç çıkışı radyal mesafelerde ortalama değerler a) sıcaklık b) hız ortalama değerleri (Average values of the torch exit a) temperature b) velocity values) 
amaçlanmıştır. Farklı akım değerlerine göre hesaplanan ortalama sıcaklık ve hızlardaki değişim grafikleri Şekil 9'da verilmiştir. Şekilde görüldüğü üzere artan akım değeri ile ortalama sıcaklığın arttığı, ancak yüksek değerlerde sicaklık artışının çok az olduğu görülmektedir. 100 A akımda $7374 \mathrm{~K}$ olan ortalama sicaklık, 200 A akımda $10703 \mathrm{~K}$ iken, $250 \mathrm{~A}$ akımda $11041 \mathrm{~K}$ olmuştur. Akım artışı ile sıcaklık arasında doğrusal bir ilişki olmadığı tespit edilmiştir. Şekil 9'da sunulmuş olan hız grafiği değerlendirildiğinde, hız değerlerinin akımın artışı ile arttığı ancak 250 A olan en yüksek akım değerinde bir miktar azalma olduğu tespit edilmiştir. $\mathrm{Bu}$ azalmanın nedeninin ark kökü bağlantı noktasının konumu ile ilişkili olabileceği değerlendirilmiştir. 100 A akımda 1070 m/s olan hizın 200 A akımda 1325 m/s değerine çıktığı görülmüş olup, artışın doğrusal olmadığ1 tespit edilmiştir. Plazma atomizasyon işlemine yönelik olarak analiz edilen torç için çıkış kesitindeki ortalama sıcaklık ve ortalama hızın birlikte önem taşıdığından yola çıkarak en uygun çalışma parametrelerinin değerlendirilmesi yapıldı̆̆ında makalede sunulan geometri, boyut, akım ve gaz debisi değerleri için atomizasyon işlemi açısından $200 \mathrm{~A}$ akım değerinin daha uygun olacağı tespit edilmiştir.

\section{SONUÇLAR CONCLUSIONS)}

Bu çalışmada gaz giriş debisi ve akım yoğunluğunun plazma torcu içindeki gaz hızı, sıcaklık ve ark kökü oluşumuna etkisi parametrik olarak incelenmiş ve aşağıdaki sonuçlar elde edilmiştir.

Artan akım yoğunluğu ve hacimsel debiyle torç çıkışındaki sıcaklık ve hızın artma eğiliminde olduğu, fakat artışın düzenli olmadığı görülmüştür. Ortama giren hacimsel debinin artmasıyla torç çıkış kesitinde plazma jetinin ortalama sıcaklığının arttığı gözlemlenmiştir.

Artan debiyle ark kökünün torç çıkışına kaydığı görülmüştür ve ark boyunun uzadığı ve bunun neticesinde çıkışa ulaşan enerjinin artmasıyla hız ve sıcaklıkta artış olduğu tespit edilmiştir. Artan akım değerleriyle ark oluşum noktasının çıkışa doğru kaydığı gözlenmiştir.

Torç içinde ve çıkış kesitinde sıcaklık ve hızın radyal mesafeye göre değişiminin simetrik olmadı̆̆ 1 tespit edilmiş olup, bunun nedeninin ark kökünün anot duvarına temas ettiği nokta ile ilgili olduğu belirlenmiştir.

\section{SIMGELER (SYMBOLS)}

$\begin{array}{ll}\rho & : \text { yoğunluk }(\mathrm{kg} / \mathrm{m} 3) \\ \mathrm{V} & : \text { hız }(\mathrm{m} / \mathrm{s}) \\ \mathrm{j} & : \text { akım yoğunluğu }(\mathrm{A} / \mathrm{m} 2) \\ \mathrm{B} & : \text { Manyetik alan }(\mathrm{T}) \\ \overleftrightarrow{\tau} & : \text { Gerilme tensörü }(\mathrm{Pa}) \\ \sigma & : \text { Elektrik iletkenliği }(1 / \Omega \mathrm{m}) \\ \mathrm{E} & : \text { Elektrik alan }(\mathrm{V} / \mathrm{m}) \\ \emptyset & : \text { Elektrik Potansiyeli }(\mathrm{V}) \\ \mathrm{K} & : \text { Türbülans kinetik enerjisi } \\ \varepsilon & : \text { Türbülans yayınım oranı }\end{array}$

$\mu \quad$ : Dinamik viskozitesi (N.s/m2)

$\mu_{\mathrm{t}} \quad$ : Türbülans vizkozitesi (N.s/m2)

\section{TEŞEKKÜR (ACKNOWLEDGEMENT)}

$\mathrm{Bu}$ çalışma TÜBİTAK 1001 - BİLIMSEL VE TEKNOLOJIK ARAŞTIRMALARI DESTEKLEME PROGRAMI tarafindan 215M895 numarası ile desteklenen proje kapsamında yapılmıştır.

\section{KAYNAKLAR (REFERENCES)}

1. Li He-Ping., Pfender E., Chen Xi., Application of Steenbeck's minimum principle for three-dimensional modelling of DC arc plasma torches, Journal of Physics D: Applied Physics, 36 (9) ,1084-1096, 2003.

2. Topal H., Plasma gasification technology for solid waste disposal, Journal of the Faculty of Engineering and Architecture of Gazi University, 30 (4), 733-741, 2015.

3. Gençer G.M., Karadeniz S., Lambrecht Yurt F., Havıtçıŏlu H., Özkal S., Baskın H., The effects of plasma immersion ion implantation and deposition (PIII\&D) process voltages on the morphology, phase formation and $E$. coli adhesion of Ag coatings obtained on the surface of Ti6Al4V orthopedic implant material in nitrogen plasma, Journal of the Faculty of Engineering and Architecture of Gazi University, 32 (1), 231-241, 2017.

4. Harry J.E., Introduction to plasma technology, WileyVCH, Weinheim, Germany, 2010.

5. Selvan B., Ramachandran K., Sreekumar K.P., Thiyagarajan T.K., Ananthapadmanabhan P.V., Numerical and experimental studies on DC plasma spray torch, Vacuum, 84 (4), 444-452, 2009.

6. Ramachandran K., Marqués J.L., Vaßen R., Stöver D., Modelling of arc behaviour inside a F4 APS torch, Journal of Physics D: Applied Physics, 39 (15), 33233331, 2006.

7. Guo Z., Yin S., Liao H., Gu S., Three-dimensional simulation of an argon-hydrogen DC non-transferred arc plasma torch, International Journal of Heat and Mass Transfer, 80, 644-652, 2015.

8. Eichert P., Imbert M., Coddet C., Numerical study of an $\mathrm{ArH} 2$ gas mixture flowing inside and outside a dc plasma torch, Journal of thermal spray technology, 7 (4), 505-512, 1998.

9. Meillot E., Guenadou D., Bourgeois C., Threedimension and transient DC plasma flow modeling, Plasma Chemistry and Plasma Processing, 28 (1), 69-84, 2008.

10. Paik S., Huang P.C., Heberleinand J., Pfender E., Determination of the arc-root position in a DC plasma torch, Plasma chemistry and plasma processing, 13 (3), 379-397, 1993.

11. Gonzalez J.J., Freton P., Gleizes A., Comparisons between two-and three-dimensional models: gas injection and arc attachment, Journal of Physics D: Applied Physics, 35, 3181-3191, 2002.

12. Park J., Heberlein J., Pfender E., Candler G., Chang C. H., Two-dimensional numerical modeling of directcurrent electric arcs in nonequilibrium, Plasma 
Chemistry and Plasma Processing, 28(2), 213-231, 2008.

13. Huang R., Fukanuma H., Uesugi Y., Tanaka Y., An improved local thermal equilibrium model of DC arc plasma torch, IEEE Transactions on Plasma Science, 39 (10), 1974-1982, 2011.

14. Boulos M.I., Fauchais P., Pfender E., Thermal plasmas: fundamentals and applications, Springer Science \& Business Media, New York, A.B.D., 2013.
15. Selvan B., Ramachandran K., Comparisons between two different three-dimensional arc plasma torch simulations. Journal of thermal spray technology, 18 (56), 846-857, 2009.

16. Sunjuq W.K.W., Argon DC taşınımsız ark plazma torcunun üç boyutlu simülasyonu, Yüksek lisans tezi, Gazi Üniversitesi, Fen Bilimleri Enstitüsü, Ankara, 2016. 
